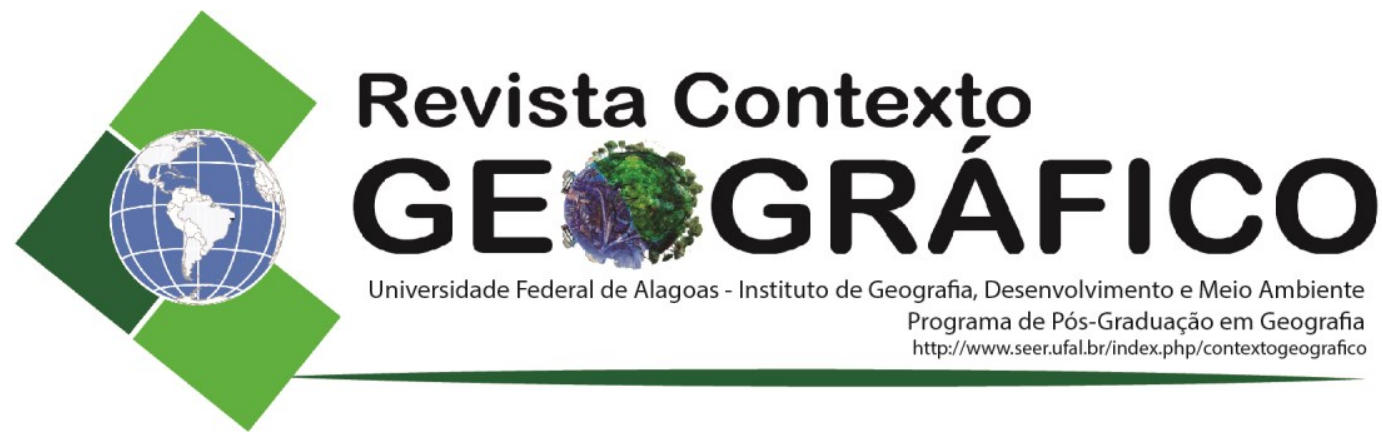

\title{
RISCO DE CONTAMINAÇÃO DE ÁGUAS SUBTERRÂNEAS POR BTEX EM MACEIÓ-AL
}

\author{
Rosane Cunha Maia Nobre \\ Universidade Federal de Alagoas, Instituto de Geografia, Desenvolvimento e Meio Ambiente \\ Maceió, AL, Brasil \\ rosanemaia@igdema.ufal.br
}

Mayra Abreu Gouveia

Universidade Federal de Alagoas, Centro de Tecnologia, Maceió, AL, Brasil

mayraabreu92@gmail.com

\begin{abstract}
RESUMO - Na cidade de Maceió-AL, verificou-se que a elevada quantidade de postos de combustíveis numa determinada área pode contribuir para riscos de vazamento de compostos tóxicos para o solo e as águas subterrâneas. Este problema vem se agravando devido à dificuldade de monitoramento periódico da integridade dos tanques de armazenamento subterrâneo de combustíveis. A maior preocupação é a introdução dos hidrocarbonetos voláteis BTEX (benzeno, tolueno, etilbenzeno e os xilenos) no manancial subterrâneo que podem provocar impactos negativos tanto no ecossistema local quanto na economia. A exposição humana à estes poluentes pode ocasionar complicações na saúde devido ao alto teor de toxicidade e propriedades cancerígenas. Este trabalho teve o objetivo de apresentar uma metodologia de cálculo do índice de risco de contaminação das águas subterrâneas por BTEX na cidade de Maceió-AL, com uso de geoprocessamento (SIG). Foi realizado o mapeamento de variáveis determinantes, georreferenciados por 50 bairros do município, tais como: quantidade de postos de combustíveis e de poços de abastecimento de água, densidade demográfica e a profundidade do lençol freático. Este último teve maior influência nos resultados do mapa final do índice de risco, obtido por análise espacial dos mapas temáticos.
\end{abstract}

Palavras-chave: Benzeno; Contaminação; Postos de combustível, SIG.

\section{RISK OF CONTAMINATION OF UNDERGROUND WATERS BY BTEX IN MACEIÓ-AL}

\begin{abstract}
In the city of Maceio-AL, it has been verified that the large number of gas stations in a specific area could contribute to a high potential in the infiltration of toxic compounds into the soil and groundwater. This problem has become even more serious due to the difficulty in periodic monitoring of existing underground storage tanks (USTs) integrity. The major concern is the introduction of volatile hydrocarbons like BTEX (benzene, toluene, ethylbenzene and xylenes) in groundwater that might cause negative impacts on both the ecosystem and the local economy. Human exposure to these pollutants can cause health complications due to high levels of toxicity and carcinogenic effects. This study aimed to present a methodology for calculating a groundwater contamination risk potential by BTEX, applied to the city of Maceio-AL, using geoprocessing techniques (GIS). Thematic mapping of four determining variables has been conducted to a total of 50 municipal districts, such as: gas stations distribution and groundwater supply wells, population density and depth to water table. This latter had a greater influence on the final map, obtained by use of GIS spatial analysis.
\end{abstract}

Keywords: Benzene; Contamination; gas station; GIS. 


\section{INTRODUÇÃO}

As fontes de poluição de solo e águas subterrâneas estão associadas a uma série de atividades de origem antrópica, incluindo as industriais, agrícolas, comerciais e domésticas. A questão relativa aos tanques de armazenamento de combustíveis, sobretudo os que se encontram enterrados (USTs Underground Storage Tanks), vem sendo amplamente discutida como potenciais fontes de contaminação do subsolo.

De acordo com Coutinho e Gomes (2007), os tanques de armazenamento subterrâneo de combustíveis ficam enterrados a uma profundidade de até cinco metros. Tendo em vista que os vazamentos ocorrem, geralmente, em pequenas quantidades, passam despercebidos pelos administradores dos empreendimentos que só tomam providências quando há uma perda considerável de combustível. Diante de um derramamento de gasolina, os problemas podem ser diversos, principalmente em locais onde os lençóis freáticos estão próximos à superfície. Em Maceió, esse problema é mais acentuado na área de Planície Costeira.

A ausência de fiscalização dos órgãos responsáveis, bem como a falta de interesse dos empreendedores em realizar manutenções periódicas nesses tanques enterrados, pode ocasionar sérios problemas estruturais, relacionados com a vida útil dos tanques de armazenamento subterrâneo. No Brasil, uma mudança de postura foi verificada após a regulamentação da Resolução Conama 273 de 2000. Esta resolução reconhece que toda instalação e sistemas de armazenamento de petróleo e outros combustíveis são empreendimentos potencialmente poluidores e geradores de acidentes ambientais, onde os possíveis vazamentos causam contaminação do solo, do ar e dos mananciais subterrâneos e de superfície. Em vista disso, a resolução estabeleceu normas objetivas para a construção, instalação, ampliação e operação de postos revendedores e postos de abastecimento, para a emissão da licença de operação desses estabelecimentos.

Segundo a CETESB (1999), quando ocorre um derramamento de gasolina, a maior preocupação é a introdução dos hidrocarbonetos voláteis BTEX (benzeno, tolueno, etilbenzeno e os xilenos) nos aquíferos, em áreas de proteção de poços de recarga. Faz-se necessário o gerenciamento de áreas contaminadas (ACs) que propõe minimizar os riscos a que estão sujeitos à população e o meio ambiente. De acordo com Nobre e Nobre (2011) o risco à saúde humana, a partir da exposição aos contaminantes ambientais, pode ser de grande magnitude, com efeitos tóxicos e/ou carcinogênicos.

Maceió, situada na região costeira do Estado de Alagoas, é hoje um grande conglomerado urbano, caracterizada por ambientes sensíveis, com praias arenosas, estuários e enseadas, compondo uma área de grande potencial turístico, assegura Nobre et al. (2007). A cidade é abastecida por um único sistema aquífero que compreende um ambiente geológico heterogêneo. Verifica-se que o uso de águas subterrâneas na cidade já ultrapassou os limites seguros de sustentabilidade hídrica. De acordo com Nobre et al. (2007), os mananciais subterrâneos de Maceió vêm sofrendo um processo contínuo de degradação e diminuição de suas reservas, decorrente da perfuração não controlada de poços tubulares nos últimos 30 anos. Já foi constatado que o atual sistema de extração tem causado perturbações significativas na hidráulica do sistema aquífero regional, a exemplo de processos de intrusão marinha, com a detecção de elevados níveis de cloretos em muitos poços de abastecimento urbano.

Segundo a CASAL (2016), 68\% do abastecimento da capital alagoana são provenientes do uso de águas subterrâneas, com cerca de 200 unidades de poços. O aquífero urbano vem sendo cada vez mais utilizado, à medida que a população vai crescendo, com o aumento de perfurações clandestinas de poços tubulares.

A gasolina derramada, por não se misturar completamente, e contendo mais de uma centena de componentes (cerca de 22 substâncias), estará inicialmente presente no subsolo como líquido de fase livre não aquosa (NAPL). Após a infiltração, pode atingir a água subterrânea, com movimentação que levará a migração vertical pela zona não saturada até atingir o lençol, se não houver 
impedimentos geológicos. A partir da fase livre uma parte dos compostos vai se solubilizar. Mesmo com solubilidade bastante reduzida os valores encontrados nas águas subterrâneas provenientes deste tipo de contaminação estão muito acima dos valores tolerados. Os compostos BTEX são os mais solúveis e são de alguma forma perigosos: o benzeno é considerado o mais tóxico e um composto classificado como carcinogênico enquanto tolueno, etilbenzeno e xileno são classificados como tóxicos, afirma Finotti et al. (2001).

A Portaria 2914/2011, do Ministério da Saúde, estabelece os seguintes limites permitidos para os hidrocarbonetos em água potável: $5 \mu \mathrm{g} / \mathrm{L}$ no caso do benzeno, $170 \mu \mathrm{g} / \mathrm{L}$ para o tolueno, $200 \mu \mathrm{g} / \mathrm{L}$ para o etilbenzeno e $300 \mu \mathrm{g} / \mathrm{L}$ para o xileno.

Maciel et al.(2015) considera que o petróleo e seus derivados causam um dos mais graves acidentes ambientais. Atualmente tem-se observado uma grande preocupação relacionada à sustentabilidade. Diante disto, o estudo de caso desse trabalho tem objetivo de agir de maneira preventiva em busca da mitigação de acidentes ambientais gerados por postos de combustíveis.

De acordo com a Agência Nacional do Petróleo (ANP), o Brasil possui 18 refinarias de petróleo, 383 usinas de etanol e 40.894 revendedores varejistas de combustíveis líquidos. Maceió possui 275 registros encontrados de postos revendedores, contudo para este estudo de caso foram cadastrados 159 (que estão em operação) e distribuídos por bairro em Maceió.

Portanto, visto a intensidade dos problemas gerados pela contaminação do subsolo, a metodologia deste trabalho propõe identificar os bairros de Maceió-AL com maior potencial de contaminação de suas águas subterrâneas por BTEX, com origem de vazamentos de postos de combustíveis. Objetivo é proteger os mananciais subterrâneos e auxiliar em ações preventivas para proteção da população em risco, bem como o controle da contaminação.

\section{METODOLOGIA}

Foram elaborados quatro mapas temáticos, tais como: mapeamento dos postos de combustíveis, mapeamento da densidade demográfica, mapeamento dos poços de abastecimento de água e mapeamento do nível estático. Para a elaboração dos mesmos, foi utilizado o sistema de informações geográficas (SIG) com uso do programa ArcView versão 3.2.

Como na metodologia utilizada por Nobre (2006), todos os mapas temáticos foram elaborados em formato vetorial, em seguindo para uma conversão em formato matricial (raster ou grid) e incoporados no ArcView como mapas temáticos georeferenciados. A identificação dos atributos foi realizada através de dados decodificados em planos de informação, utilizando as ferramentas do geoprocessamento. Os mapas temáticos foram convertidos em formato matricial através da fragmentação e uma série de píxeis, com uma discretização de 20 metros e um valor numérico atribuído a cada pixel. O arquivo matricial correspondente é composto por uma série de valores numéricos que podem ser lidos e processados pelo programa de análise espacial do ArcView.

De acordo com a quantificação dos quatro mapas, a caracterização dos atributos recebeu um índice numérico (nota) que variou de 1 a 10, sendo 10 a pior situação (maior risco), grau de importância para o estudo. A atribuição de notas é sumarizada, e por meio de técnicas de geoprocessamento é efetuada a integração entre os mapas realizada no ArcView, obtendo o resultado final que consiste no mapa do índice de risco de contaminação por BTEX, por bairro na cidade de Maceió-AL.

As informações numéricas relacionadas às variáveis do estudo de caso estão consolidadas na Tabela 1. 
Tabela 1 - Cadastro das variáveis para cálculo do índice de risco de contminação por BTEX.

\begin{tabular}{|c|c|c|c|c|c|c|c|c|}
\hline BAIRRO & $\begin{array}{l}\text { Dens_Dem } \\
\left(\mathbf{H a b} / \mathbf{K m}^{2}\right)\end{array}$ & $\begin{array}{c}\text { Notas } \\
\text { (Dens_Dem) }\end{array}$ & $\begin{array}{c}\text { Postos de } \\
\text { Combustível }\end{array}$ & $\begin{array}{c}\text { Notas } \\
\text { (postos) }\end{array}$ & $\begin{array}{c}\text { Poços de } \\
\text { Abastecimento }\end{array}$ & $\begin{array}{c}\text { Notas } \\
\text { (poços) }\end{array}$ & NE (m) & $\begin{array}{r}\text { Notas } \\
\text { (NE) }\end{array}$ \\
\hline $\begin{array}{c}\text { TABULEIRO DOS } \\
\text { MARTINS }\end{array}$ & 7557,7 & 6,0 & 22,0 & 10,0 & 19,0 & 8,0 & $>40$ & 2 \\
\hline CLIMA BOM & 12011,7 & 10,0 & 3,0 & 5,0 & 13,0 & 8,0 & $>40$ & 2 \\
\hline $\begin{array}{c}\text { PONTAL DA } \\
\text { BARRA }\end{array}$ & 916,6 & 2,0 & 2,0 & 5,0 & 0,0 & 0,0 & $0-5$ & 10 \\
\hline PRADO & 11866,9 & 10,0 & 6,0 & 8,0 & 3,0 & 4,0 & $0-5$ & 10 \\
\hline LEVADA & 12426,5 & 10,0 & 1,0 & 5,0 & 1,0 & 4,0 & $0-5$ & 10 \\
\hline PONTA GROSSA & 16987,5 & 10,0 & 2,0 & 5,0 & 0,0 & 0,0 & $0-5$ & 10 \\
\hline $\begin{array}{c}\text { VERGEL DO } \\
\text { LAGO } \\
\end{array}$ & 18542,1 & 10,0 & 1,0 & 5,0 & 0,0 & 0,0 & $0-5$ & 10 \\
\hline $\begin{array}{c}\text { TRAPICHE DA } \\
\text { BARRA }\end{array}$ & 14382,4 & 10,0 & 2,0 & 5,0 & 0,0 & 0,0 & $0-5$ & 10 \\
\hline $\begin{array}{c}\text { PONTA DA } \\
\text { TERRA } \\
\end{array}$ & 19812,3 & 10,0 & 0,0 & 0,0 & 0,0 & 0,0 & $0-5$ & 10 \\
\hline $\begin{array}{l}\text { CRUZ DAS } \\
\text { ALMAS } \\
\end{array}$ & 5217,1 & 6,0 & 4,0 & 8,0 & 10,0 & 6,0 & $0-5$ & 10 \\
\hline BEBEDOURO & 4485,7 & 4,0 & 0,0 & 0,0 & 3,0 & 4,0 & $5-20$ & 6 \\
\hline IPIOCA & 378,1 & 2,0 & 4,0 & 8,0 & 4,0 & 4,0 & $0-5$ & 10 \\
\hline PESCARIA & 708,4 & 2,0 & 0,0 & 0,0 & 3,0 & 4,0 & $0-5$ & 10 \\
\hline RIACHO DOCE & 517,2 & 2,0 & 1,0 & 5,0 & 4,0 & 4,0 & $0-5$ & 10 \\
\hline GARÇA TORTA & 838,6 & 2,0 & 0,0 & 0,0 & 0,0 & 0,0 & $0-5$ & 10 \\
\hline GUAXUMA & 504,7 & 2,0 & 1,0 & 5,0 & 0,0 & 0,0 & $0-5$ & 10 \\
\hline JACARECICA & 1773,4 & 2,0 & 1,0 & 5,0 & 2,0 & 4,0 & $0-5$ & 10 \\
\hline $\begin{array}{c}\text { BENEDITO } \\
\text { BENTES }\end{array}$ & 3576,6 & 4,0 & 2,0 & 5,0 & 23,0 & 10,0 & $>40$ & 2 \\
\hline $\begin{array}{c}\text { CIDADE } \\
\text { UNIVERSITÁRIA }\end{array}$ & 3504,8 & 4,0 & 4,0 & 8,0 & 19,0 & 8,0 & $20-40$ & 4 \\
\hline $\begin{array}{l}\text { SANTOS } \\
\text { DUMONT }\end{array}$ & 2888,0 & 4,0 & 2,0 & 5,0 & 7,0 & 6,0 & $>40$ & 2 \\
\hline RIO NOVO & 2654,5 & 4,0 & 0,0 & 0,0 & 0,0 & 0,0 & $5-20$ & 6 \\
\hline FERNÃO VELHO & 2158,6 & 4,0 & 2,0 & 5,0 & 1,0 & 4,0 & $5-20$ & 6 \\
\hline JARAGUÁ & 2368,1 & 4,0 & 8,0 & 8,0 & 1,0 & 4,0 & $0-5$ & 10 \\
\hline PAJUÇARA & 5648,7 & 6,0 & 3,0 & 5,0 & 1,0 & 4,0 & $0-5$ & 10 \\
\hline PONTA VERDE & 17740,4 & 10,0 & 5,0 & 8,0 & 2,0 & 4,0 & $0-5$ & 10 \\
\hline CENTRO & 1772,6 & 2,0 & 5,0 & 8,0 & 6,0 & 6,0 & $0-5$ & 10 \\
\hline POÇO & 11125,9 & 10,0 & 7,0 & 8,0 & 2,0 & 4,0 & $0-5$ & 10 \\
\hline BOM PARTO & 2301,4 & 4,0 & 4,0 & 8,0 & 1,0 & 4,0 & $5-20$ & 6 \\
\hline MUTANGE & 4843,5 & 4,0 & 1,0 & 5,0 & 5,0 & 4,0 & $5-20$ & 6 \\
\hline FAROL & 5604,4 & 6,0 & 15,0 & 10,0 & 28,0 & 10,0 & $20-40$ & 4 \\
\hline PITANGUINHA & 4724,0 & 4,0 & 2,0 & 5,0 & 11,0 & 8,0 & $>40$ & 2 \\
\hline $\begin{array}{c}\text { CHÃ DE } \\
\text { BEBEDOURO } \\
\end{array}$ & 16128,2 & 10,0 & 1,0 & 5,0 & 2,0 & 4,0 & $20-40$ & 4 \\
\hline $\begin{array}{c}\text { CHÃ DA } \\
\text { JAQUEIRA }\end{array}$ & 12879,9 & 10,0 & 2,0 & 5,0 & 7,0 & 6,0 & $20-40$ & 4 \\
\hline SANTO AMARO & 7423,2 & 6,0 & 0,0 & 0,0 & 2,0 & 4,0 & $>40$ & 2 \\
\hline MANGABEIRAS & 5156,1 & 6,0 & 3,0 & 5,0 & 10,0 & 6,0 & $5-20$ & 6 \\
\hline JATIÚCA & 13095,5 & 10,0 & 6,0 & 8,0 & 1,0 & 4,0 & $0-5$ & 10 \\
\hline JACINTINHO & 23554,5 & 10,0 & 5,0 & 8,0 & 26,0 & 10,0 & $20-40$ & 4 \\
\hline FEITOSA & 11768,9 & 10,0 & 3,0 & 5,0 & 10,0 & 6,0 & $>40$ & 2 \\
\hline $\begin{array}{l}\text { GRUTA DE } \\
\text { LOURDES }\end{array}$ & 4464,2 & 4,0 & 4,0 & 8,0 & 15,0 & 8,0 & $>40$ & 2 \\
\hline BARRO DURO & 6027,1 & 6,0 & 4,0 & 8,0 & 16,0 & 8,0 & $>40$ & 2 \\
\hline CANÃ̃ & 8799,3 & 6,0 & 0,0 & 0,0 & 4,0 & 4,0 & $>40$ & 2 \\
\hline OURO PRETO & 11612,0 & 10,0 & 0,0 & 0,0 & 3,0 & 4,0 & $>40$ & 2 \\
\hline PETRÓPOLIS & 5022,1 & 6,0 & 2,0 & 5,0 & 7,0 & 6,0 & $>40$ & 2 \\
\hline SERRARIA & 3002,9 & 4,0 & 7,0 & 8,0 & 26,0 & 10,0 & $>40$ & 2 \\
\hline $\begin{array}{c}\text { JARDIM } \\
\text { PETRÓPOLIS }\end{array}$ & 1896,6 & 2,0 & 0,0 & 0,0 & 0,0 & 0,0 & $>40$ & 2 \\
\hline SANTA LÚCIA & 6473,7 & 6,0 & 3,0 & 5,0 & 6,0 & 6,0 & $>40$ & 2 \\
\hline SANTA AMÉLIA & 4526,0 & 4,0 & 3,0 & 5,0 & 4,0 & 4,0 & $>40$ & 2 \\
\hline PINHEIRO & 9696,7 & 6,0 & 2,0 & 5,0 & 4,0 & 4,0 & $20-40$ & 4 \\
\hline SÃO JORGE & 3772,2 & 4,0 & 2,0 & 5,0 & 10,0 & 6,0 & $20-40$ & 4 \\
\hline ANTARES & 2841,4 & 4,0 & 2,0 & 5,0 & 6,0 & 6,0 & $>40$ & 2 \\
\hline
\end{tabular}

Segundo a ANA (2011) o município de Maceió está subdividido em 50 bairros, conforme a Figura 1. 
Figura 1. Mapa com a Identificação dos Bairros de Maceió-AL.

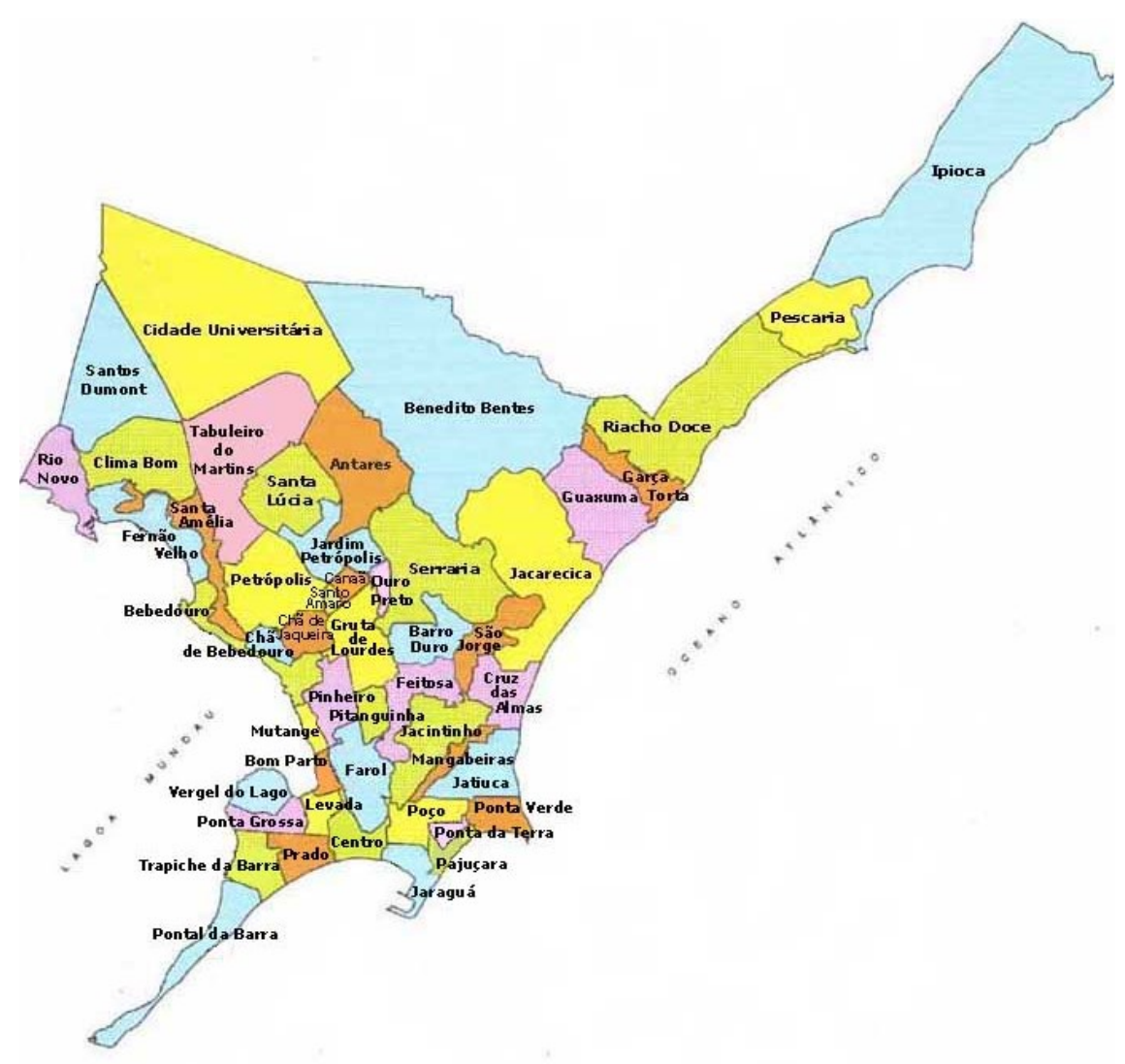

A profundidade do nível estático (NE) determina a distância que o contaminante atingirá as águas subterrâneas, portanto essencial para este estudo. Os dados de NE desse trabalho foram obtidos em relatórios de perfuração de poços tubulares do município.

Foram utilizados dados de poços tubulares da CASAL e particulares de Nobre (2006), e pesquisa realizada no SIAGAS/CPRM (Sistema de Informações de Águas Subterrâneas da Companhia de Pesquisas de Recursos Minerais) para cadastro dos poços de abastecimento de água do estudo de caso, considerando 328 poços que servem para abastecimento da população (sabendo-se que esse quantitativo está subdimensionado).

Para obtenção do mapa de densidade demográfica, foi utilizado o banco de dados do IBGE (2010). Essa variável é relevante para o estudo, que determina como a contaminação pode atingir a distribuição de pessoas (população) residentes em cada bairro.

\section{RESULTADOS E DISCUSSÃO}

Verifica-se que 15 bairros (de um total de 50) possuem elevada densidade demográfica. Isto significa que, em uma determinada área, o risco atribuído à população residente é bem maior em relação aos bairros com menor densidade demográfica. Diante disto, foram atribuídas notas de $\mathrm{N}=10$ para os 15 bairros com densidade demográfica máxima, representadas na Figura 2.

Foi realizada a distribuição por bairro para os 159 postos de combustível em operação no município. Seguindo o mesmo raciocínio, para os bairros da capital que possuem elevado número de postos, foi atribuída uma nota máxima $(\mathrm{N}=10)$. Tendo em vista a relevância desse parâmetro, e analisando a Figura 3, os bairros Farol e Tabuleiro dos Martins, onde foram atribuídas as notas máximas, 
representam significativa preocupação quando se é levada em consideração a densidade demográfica, caracterizando um risco a população no caso de um derrame de combustível.

Figura 2. Mapa Densidade Demográfica em Maceió.

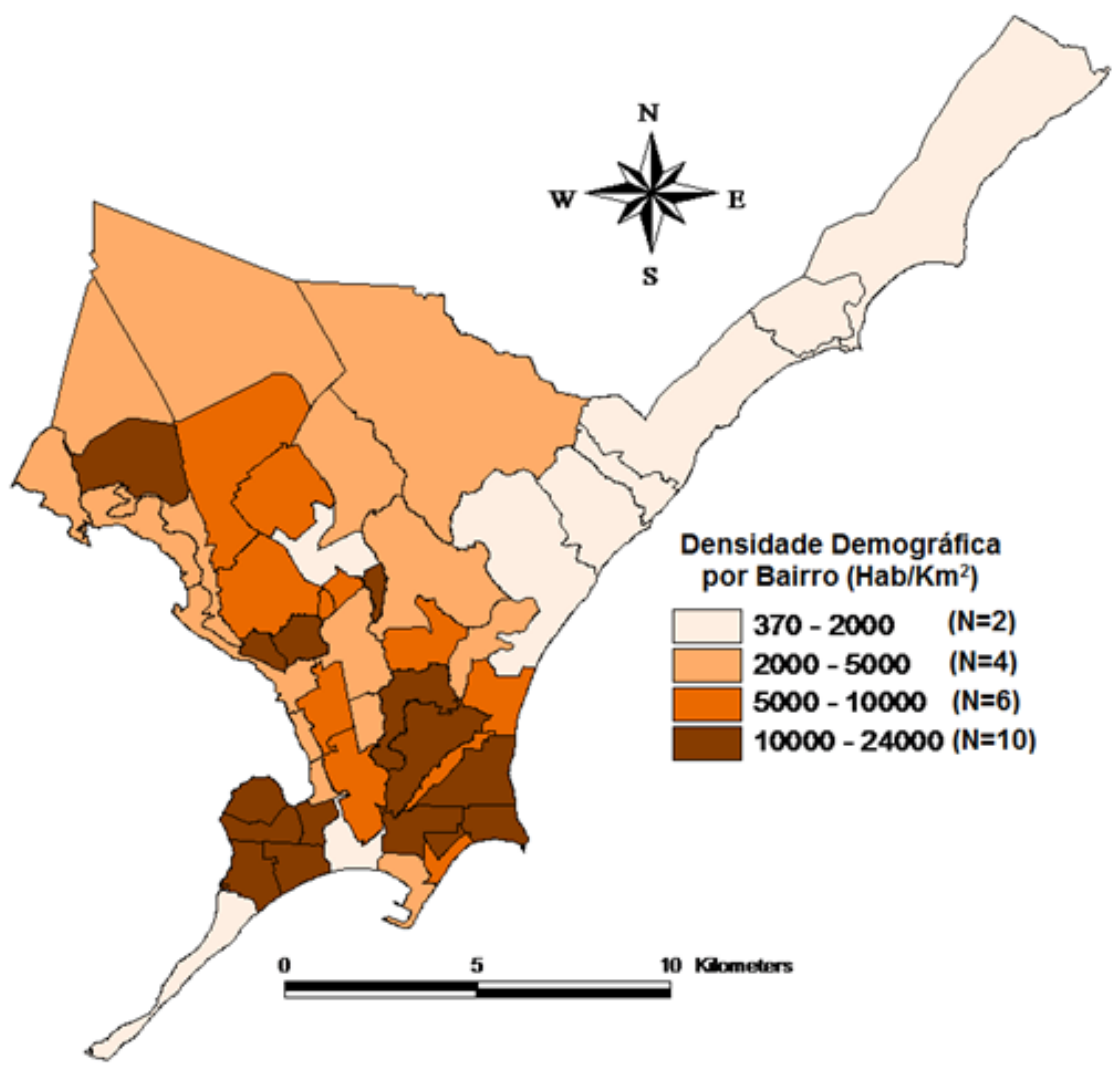

Foi considerado um cadastro de 328 poços de abastecimento de água que, distribuídos pelo município, registrou um máximo de 28 poços em um determinado bairro. Observa-se que os bairros Benedito Bentes, Farol, Jacintinho e Serraria estão representados na Figura 4 com nota máxima $(\mathrm{N}=10)$. Levando em consideração o risco de contaminação, constatou-se que o Farol foi o bairro com duas notas máximas $\mathrm{N}=10$ (nos mapas de postos de combustíveis e poços de abastecimento), estará mais vulnerável e com elevado risco de contaminação por BTEX nas águas subterrâneas e, consequentemente, em seus poços de abastecimento. Foram atribuídas notas para o nível estático (NE) de acordo com sua profundidade.

Quanto menor a profundidade, maior o risco de contaminação das águas subterrâneas. As notas variam de $2(\mathrm{NE}>40 \mathrm{~m})$ a $10(\mathrm{NE}<5 \mathrm{~m})$, classificando os bairros de acordo com a distância percorrida pelo contaminante da superfície até atingir o lençol freático.

De acordo com o mapa apresentado na Figura 5, a maior vulnerabilidade da contaminação atingir o lençol freático está no litoral de Maceió (indicado com $\mathrm{N}=10$ ) tanto pela característica do solo em ser arenoso, como também pelo nível estático encontrar-se menor que cinco metros, facilitando a infiltração do contaminante até o aquífero nesta região da planície costeira. 
Figura 3. Mapas Postos de Combustíveis em Maceió.

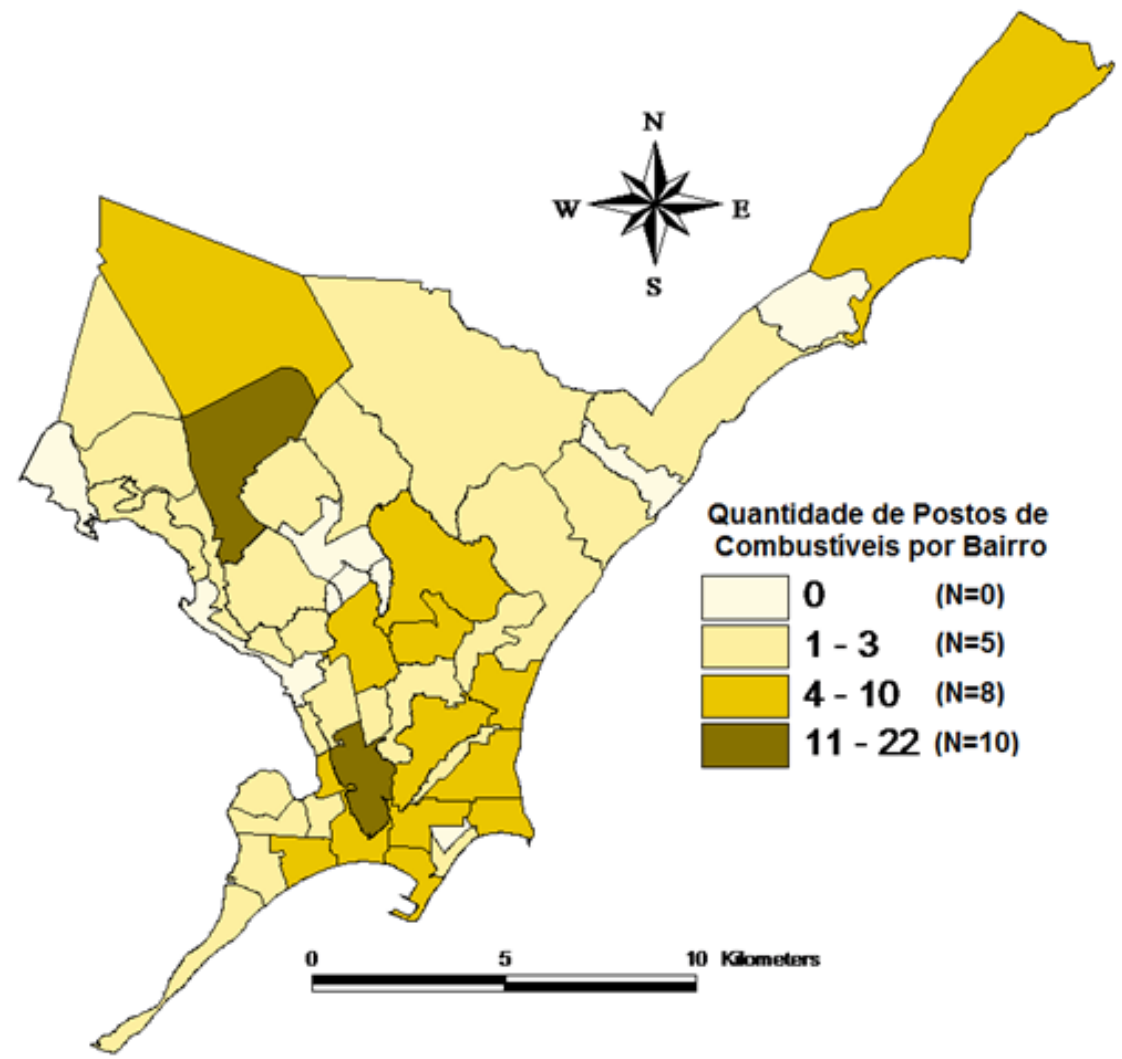

Figura 4. Distribuição de Poços de Abastecimento.

A

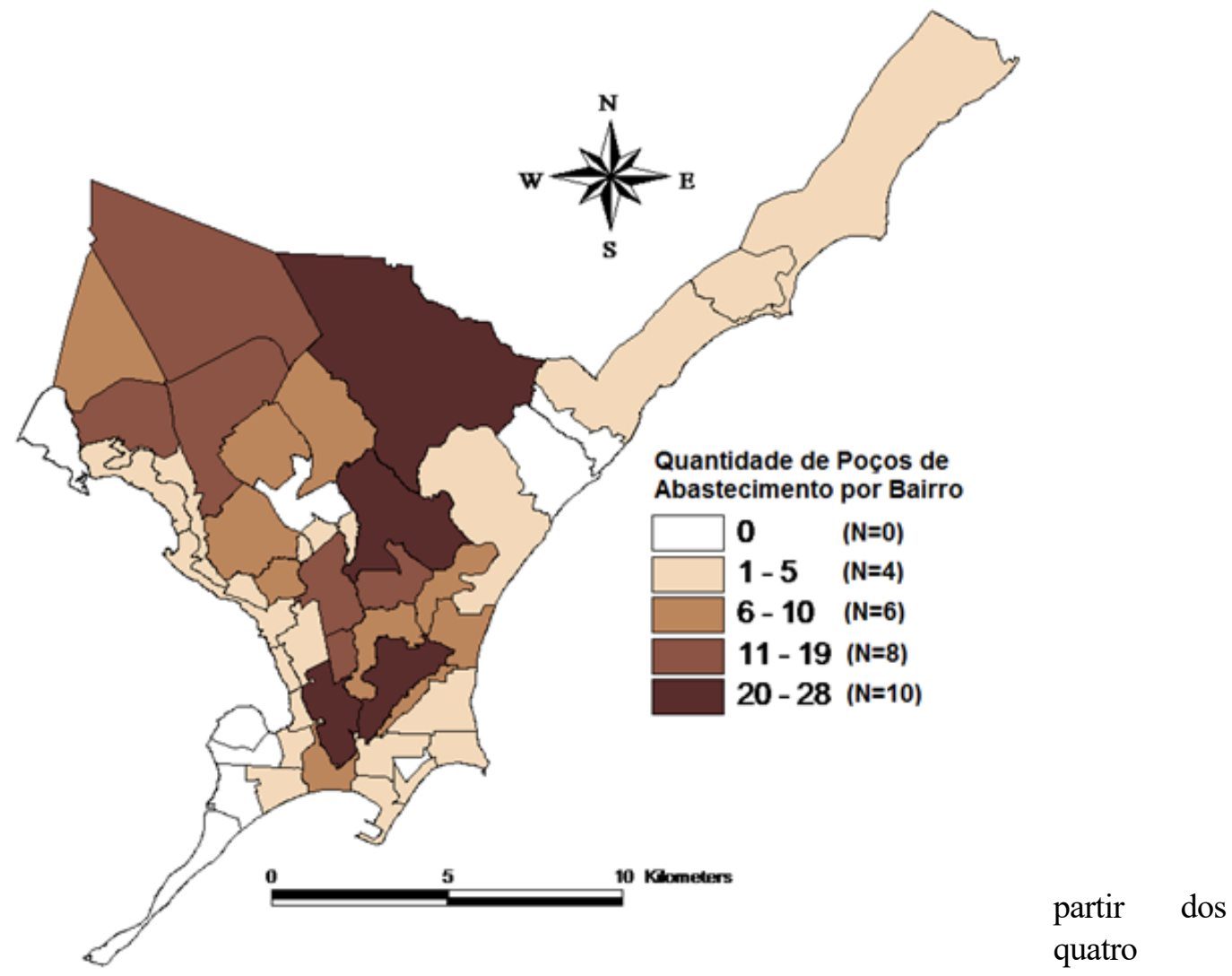


mapas, foi calculado o mapa do índice de risco de contaminação por BTEX (IRC) (Figura 6), através da seguinte articulação dos mapas temáticos: quantidade de postos de combustíveis (PC) e poços de abastecimento (PA), dados de densidade demográfica (DM) e nível estático (NE). Sendo assim, foi realizada a integração das notas dos mapas anteriores para obtenção do IRC, conforme a equação 1 , e normalizado para variar de 1 a 10.

$$
I R C=P C \times P A \times D M \times N E
$$

Figura 5. Mapa de Nível estático.

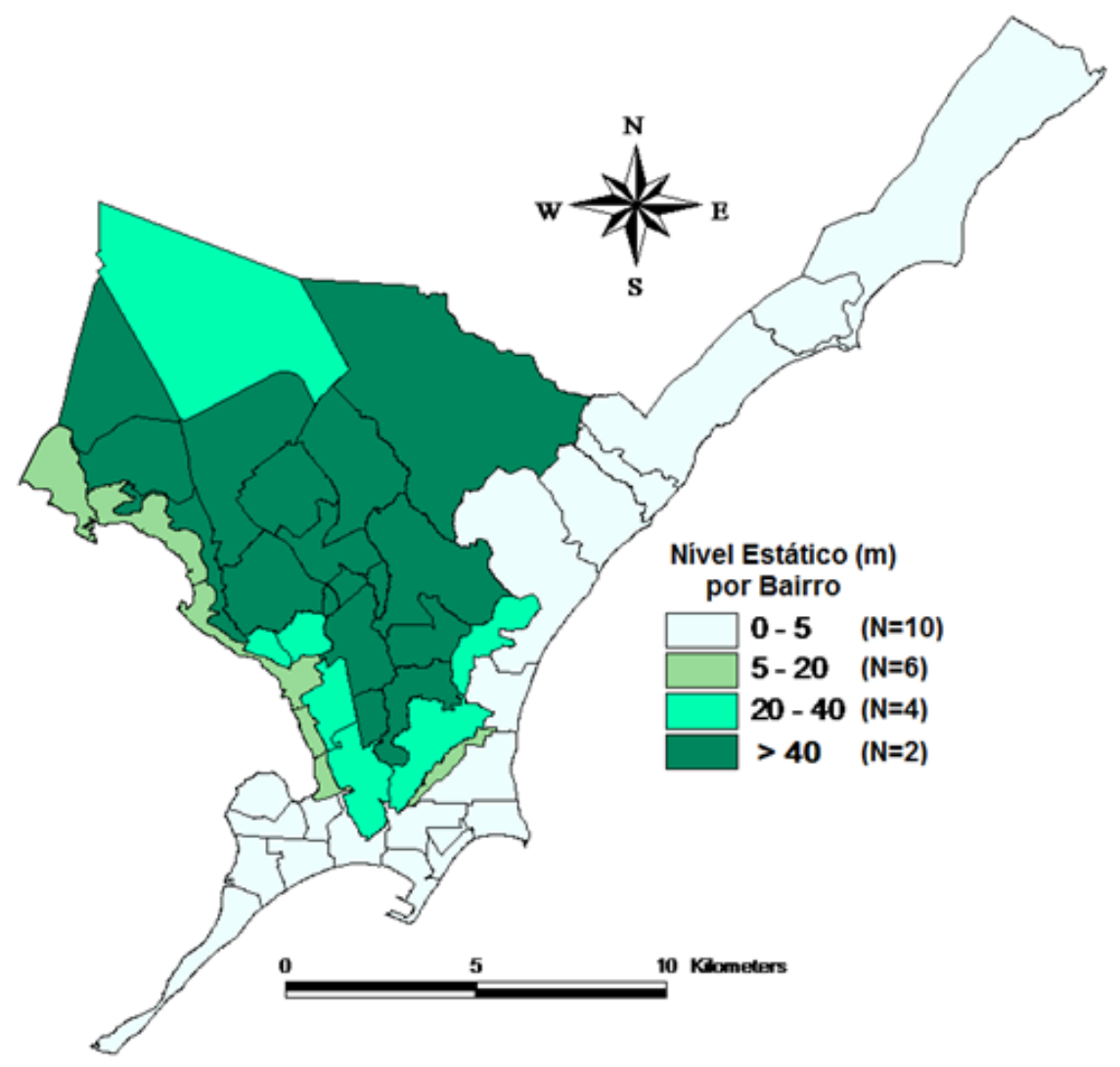

Observa-se que os 4 bairros com índice IRC muito elevado superior a 6, (Prado, Ponta Verde, Jatiúca e Cruz das Almas) estão em regiões com nível estático reduzido, representando mais de 50\% do número de bairros que apresentaram maior risco. Isto significa que o nível estático foi um parâmetro determinante para os resultados deste trabalho. Os bairros com índice muito elevado (IRC entre 6 e 10) representam $14 \%$ de risco em toda cidade, seguindo dos bairros que mostraram índice elevado (IRC entre 3 e 6) que representaram 4\%, já os bairros com índice médio (IRC entre 1 e 3 ) e índice baixo (IRC entre 0 e 1) foram equivalentes a $24 \%$ do total, e os bairros com índice isento (IRC entre 0) corresponderam a $34 \%$ de risco. Verifica-se também que se não há postos de combustíveis ou ausência dos poços de abastecimento, não haverá risco de contaminação das águas subterrâneas por BTEX.

Segundo os processos de licenciamento do órgão ambiental estadual, no ano de 2016 já foram registrados 4 novos casos de contaminação por postos de combustíveis em Maceió. Os bairros que representam os casos são: Prado (Índice Muito Elevado), Centro (Índice Médio); Mangabeiras (Índice Médio); Trapiche da Barra (Isento). De todos os bairros apresentados, apenas a Mangabeiras não está em região de risco elevado, ainda assim representando uma nota alta. O bairro Trapiche da 
Barra mostrou índice isento devido à ausência até o momento do cadastro de poços de abastecimento de água, entretanto não isentou o solo de contaminação.

Figura 6. Mapa do Índice de Risco de Contaminação por BTEX

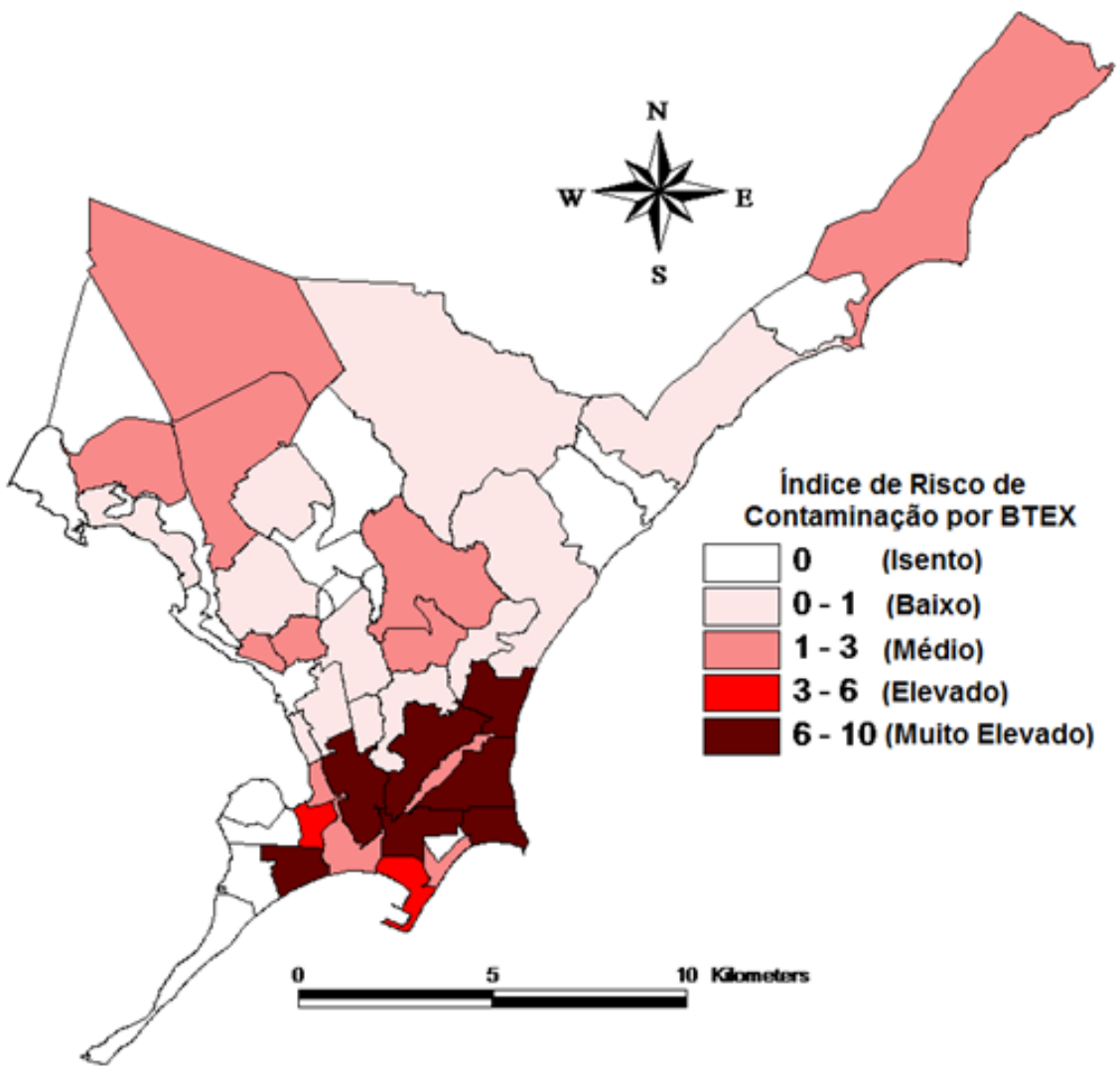

\section{CONSIDERAÇÕES FINAIS}

A avaliação de um índice de risco de contaminação das águas subterrâneas por compostos específicos (no caso o BTEX) pode ser útil no rastreamento de áreas com uso intensivo do manancial subterrâneo para o abastecimento público. Essas águas podem estar expostas às substâncias tóxicas oriundas do vazamento de combustíveis, e de outras fontes potenciais de superfície, de difícil detecção. Técnicas de geoprocessamento são ferramentas valiosas na área da Engenharia Ambiental, pois promovem a visualização dos dados de forma espacial e sistemática no domínio de estudo. Portanto, ao conhecer o risco potencial à contaminação em determinado bairro, pode-se orientar os gestores dos postos de combustíveis, bem como dos órgãos fiscalizadores para realizarem medidas preventivas, buscando evitar ocorrências de ações antrópicas.

\section{AGRADECIMENTOS}

Os autores agradecem à UFAL pela bolsa de Iniciação Científica (bolsa PIBIC) concedida à segunda autora.

\section{REFERÊNCIAS}

ANA - Agência Nacional de Águas (2011). Estudos Hidrogeológicos para Subsidiar a Gestão Sustentável dos Recursos Hídricos Subterrâneos na Região Metropolitana de Maceió. Vol. I - Aspectos Gerais da Área do Projeto. Brasília: ANA, SIP, 2011. 
ANP - AGÊNCIA NACIONAL DO PETRÓLEO (2016). Consulta postos web. Disponível em: < http://www.anp.gov.br/?id=1086>. Acessado em Novembro de 2015.

BRASIL. MINISTÉRIO DA SAÚDE (2011). Portaria no 2914 - Dispõe sobre os procedimentos de controle e de vigilância da qualidade da água para consumo humano e seu padrão de potabilidade, Brasília, 2011.

CETESB - Companhia de Tecnologia de Saneamento Ambiental (1999). O gerenciamento de áreas contaminadas. Disponível em: <http://www.cetesb.sp.gov.br>. Acessado em Março de 2016.

COMPANHIA DE SANEAMENTO DE ALAGOAS - CASAL (2016). Capital. Disponível em: < http://casal.al.gov.br/capital/>. Acessado em Janeiro de 2016.

COUTINHO, R.C.P; GOMES, C.C. (2007). Técnicas para remediação de aquíferos contaminados por vazamentos de derivados de petróleo em postos de combustíveis. In: Anais do XVII Simpósio Brasileiro de Recursos Hídricos. São Paulo, 2007.

CPRM - COMPANHIA DE PESQUISA DE RECURSOS MINERAIS (2016). Sistema de Informações de Águas Subterrâneas. Disponível em: <http://siagasweb.cprm.gov.br/layout/visualizar_mapa.php>. Acessado em Janeiro de 2016.

FINOTTI, A. R.; CAICEDO, N. O. L.; RODRIGUEZ, M. T. R. (2001). Contaminações Subterrâneas com Combustíveis Derivados de Petróleo: Toxicidade e a Legislação Brasileira. RBRH - Revista Brasileira de Recursos Hídricos Volume 6 n.2 Abr/Jun 2001, 29-46.

INSTITUTO BRASILEIRO DE GEOGRAFIA E ESTATÍSTICA (IBGE). Censo Demográfico 2010. Disponível em: <http://www.censo2010.ibge.gov.br/apps/mapa/>. Acessado em 20 de Novembro de 2015.

MACIEL, A. G. P. C.; SOBREIRA, D. E. L. S.; PACHECO, G. A. G.; PONTES, L. F. M.; SILVA, P. L.; SILVA, G. S. (2015). Contaminação Do Subsolo Por Hidrocarbonetos Do Petróleo. Ciências exatas e tecnológicas | Maceió | v. 3 | n.1 | p. 57-64 | Novembro 2015.

NOBRE, R.C.M.; ALMEIDA, M. S. S. (2007). Análise de Risco como Critério de Remediação de um Sítio Contaminado por BTEX. In: Anais do VI Congresso Brasileiro de Geotecnia Ambiental. REGEO` 2007, 1821 Junho 2007, Recife-PE, 2007.

NOBRE, R.C.M., ROTUNNO FILHO, O.C., MANSUR, W.J., NOBRE, M.M.M., COSENZA, C.A.N. (2007). Groundwater Vulnerability and Risk Mapping Using GIS, Modeling and a Fuzzy Logic Tool. Journal of Contaminant Hydrology, 94: 277-292.

NOBRE, R. C.M.; NOBRE, M.M. (2011). Groundwater and Health Implications of Biofuels Production. In: Environmental Impact of Biofuels, Cap. 7., p.123-136. InTech Open.

NOBRE, R. C. M. (2006). Avaliação de risco para o uso e proteção de aquíferos. Estudo de caso: Região Metropolitana de Maceió-AL. Tese de Doutorado, Dpt. Eng. Civil, COPPE/UFRJ, 296p. 